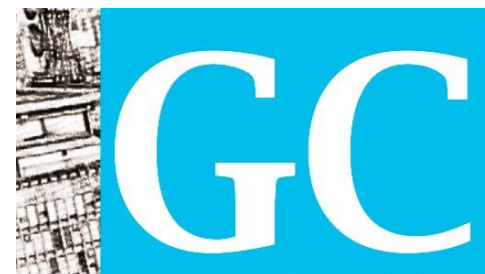

Revista Nacional de

Gerenciamento de Cidades

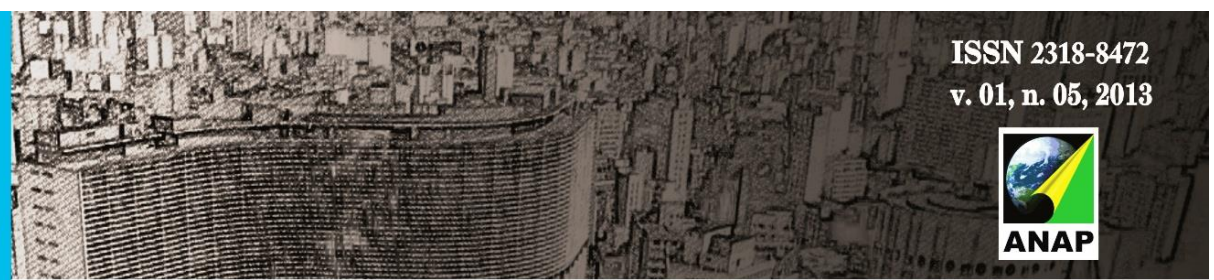

\title{
LIXÃO: TEM SOLUÇÃO?
}

\section{Leonice Seolin Dias ${ }^{1}$}

\section{Maurício Dias Marques ${ }^{2}$}

\section{Lucas Seolin Dias ${ }^{3}$}

RESUMO: A destinação final inadequada dos resíduos sólidos pode causar riscos ao meio ambiente e à saúde pública. Para tratamento e disposição final do lixo urbano, o lixão é a forma mais maléfica, pois propicia ambiente ideal para proliferação de insetos e outros animais que, direta ou indiretamente, causam doenças. Este trabalho aborda a influência dos lixões de Tupã e de Presidente Prudente na salubridade da população circunvizinha a esses ambientes. Os fatores considerados nos estudos foram bióticos (baratas, moscas e ratos) e abióticos (fumaça e odores). Em Tupã, o levantamento dos dados ocorreu de maio/ junho de 2001, utilizando-se um questionário com 10 quesitos aplicados a 30 moradores circunvizinhos ao lixão. As principais questões foram respondidas com simples sim ou não para os quesitos considerados. De igual modo, em Presidente Prudente, exceto o período, que foi de novembro/dezembro de 2010. Comparando os resultados dos dois locais,

\footnotetext{
1 Doutoranda em Geografia pela Universidade Estadual Paulista (UNESP) de Presidente Prudente (SP). (nseolin@gmail.com).

${ }^{2}$ Especialista em Direito Tributário e Administração Empresarial. Bacharel em Direito, Administração, Ciências Contábeis. Professor da Faculdade de Ciências Contábeis de Lucélia. (mdmarques1985@gmail.com).

${ }^{3}$ Especialista em Gestão de Marketing e Comunicação Integrada. Bacharel em Direito. Graduação em Comunicação Social pela Universidade Estadual de Londrina (UEL). (lucas_seolin@yahoo.com.br).
} 

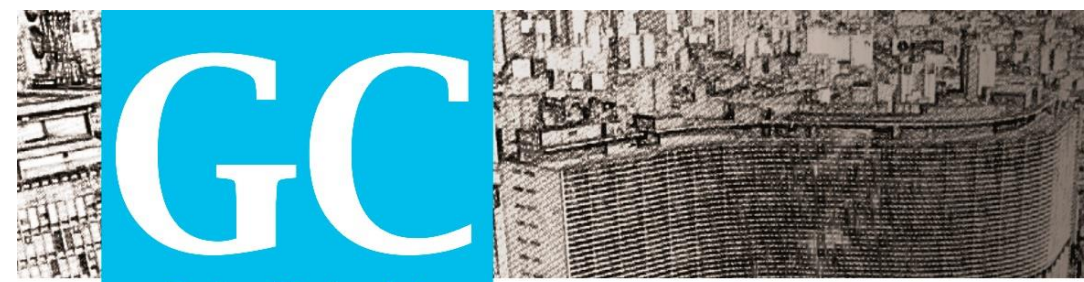

Revista Nacional de

Gerenciamento de Cidades

observa-se que diferem com relação à presença de ratos e baratas nas residências. Já as menções para moscas e fatores abióticos (odores e fumaça), praticamente foram iguais para os moradores dos dois municípios estudados. Como ocorreu com a implantação politicamente correta do programa de coleta seletiva do lixo, reciclagem e destinação final dos resíduos orgânicos para o aterro sanitário municipal de Tupã, infere-se que a solução para os lixões se efetiva na vontade política e destinação de recursos para implantação de sistemas tecnicamente adequados de disposição final do lixo, além da educação ambiental. Essa atitude pode trazer enormes benefícios ao meio ambiente e à saúde da população.

Palavras-chave: Meio ambiente. Lixão urbano. Educação Ambiental.

\section{INTRODUÇÃO}

Em todo mundo os problemas apresentados pelos resíduos sólidos, principalmente quanto ao seu destino, vêm sendo sistematicamente considerados, uma vez que se tornou um dos maiores desafios urbanos da atualidade.

Com a maioria das pessoas vivendo nas cidades e com o avanço mundial da indústria provocando mudanças nos hábitos de consumo da população, gera-se um lixo diferente em quantidade e diversidade (IPT/CEMPRE, 1995). E, a disposição incorreta desse material propicia condições favoráveis à ação de múltiplos fatores que, juntos, causam inconvenientes à saúde e ao bem estar da população.

Tavares e Barros Jr (2000), ressaltam que:

[...] até recentemente o problema do lixo deixava transparecer despercebido pela humanidade, uma vez que o volumoso lixo que produzia era muitas situações e continua sendo, lançado sem grandes preocupações em mares, rios ou em qualquer "área vazia" sem consciência das implicações para o meio ambiente. 

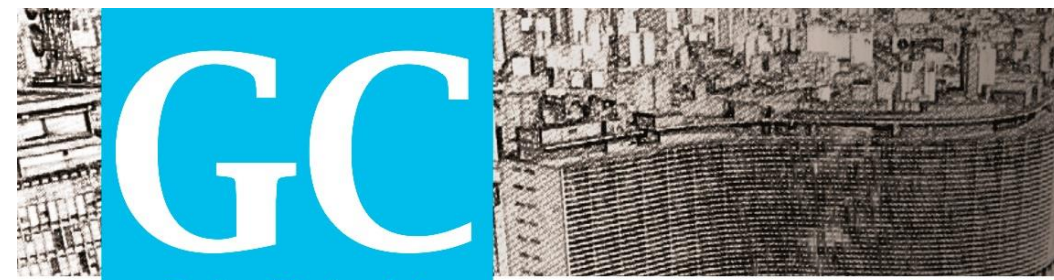

Revista Nacional de

Gerenciamento de Cidades

No Brasil, segundo a Pesquisa Nacional de Saneamento Básico (PNSB, 2000), divulgada pelo Instituto Brasileiro Geografia e Estatística (IBGE) em 2002, quase 70\% dos resíduos gerados nas grandes cidades são destinados aos lixões e alagados.

O lixão é um espaço aberto, localizado geralmente na periferia das cidades, onde o lixo fica apodrecendo ou é queimado, causando grande poluição do ar, do solo e das águas (IPT/CEMPRE, 1995). Os restos de comida costumam servir para a alimentação de animais, como porcos e aves, que depois são vendidos para o consumo da população, disseminando diversas doenças.

Esses depósitos, pelo fato de sua área estar repleta de substrato, rico em matéria orgânica, de alto teor energético, propiciam um ambiente ideal para a proliferação de insetos, especialmente dípteros muscóides (moscas) que são vetores de inúmeros patógenos para o homem e animais.

Não devemos esquecer que a presença de um lixão e a ação de catadores no local, impedindo a cobertura imediata do lixo, podem resultar em situações mais insalubres para as populações que residem no entorno dessas áreas degradadas.

O estudo realizado em Tupã (SP), por Seolin e Hamada (2006), com 30 moradores circunvizinhos ao lixão, com objetivo de avaliar a influência do antigo lixão, sobre as condições de salubridade da população circunvizinha, considerando-se as condições antes e após a desativação do lixão e instalação do novo aterro sanitário, trouxe os seguintes resultados: número significativo de moradores que identificaram a presença de fatores insalubres, representando $33,3 \%$ para ratos, $76,7 \%$ para baratas, $86,7 \%$ para moscas, $90 \%$ para odores fétidos e $90 \%$ para a fumaça.

Como o intuito de exemplificar, observa-se, diante dos resultados acima, que um lixão urbano além de causar sérios danos ao meio ambiente, ainda, pode causar transtornos não só ao local, como às comunidades vizinhas.

\section{OBJETIVOS}


Revista Nacional de

Gerenciamento de Cidades

O presente trabalho tem como objetivo: a) Avaliar a influencia de dois lixões (Tupã e Presidente Prudente) sobre as condições de salubridade da população circunvizinha. Os fatores considerados nos estudo foram bióticos (baratas, moscas e ratos) e abióticos (fumaça e odores). b) Apresentar discussão de possível solução para eliminação de lixões.

\section{METODOLOGIA}

\section{Lixão urbano de Tupã:}

Durante o período de 2000 a 2003 o município da Estância Turística de Tupã contou com um sistema de disposição final de resíduos sólidos urbanos que se enquadrou como "lixão", em função das características operacionais e pela ausência de dispositivos de impermeabilização e drenagem de chorume e gases. Esse depósito de resíduos estava a seis quilômetros do centro a cidade, e de fácil acesso. Nesse período, a quantidade de lixo disposto diariamente era de $35 \mathrm{t} / d i a$, totalizando, na disposição, durante o período de operação, $33.600 \mathrm{t}$, que ocuparam uma área de $25.465 \mathrm{~m}^{2}$.

O lixão em que se concentravam os catadores localizava-se na periferia da área urbana, tendo como vizinhos uma área urbanizada com população aproximada de 5.500 habitantes. Além das residências, outras estruturas urbanas situam-se nas proximidades. Em um raio de 500 m, foram identificados bairros como Antônio Pereira Gaspar, Jardim Aritana e Jardim Apoena (Figuras 1 e 2). 

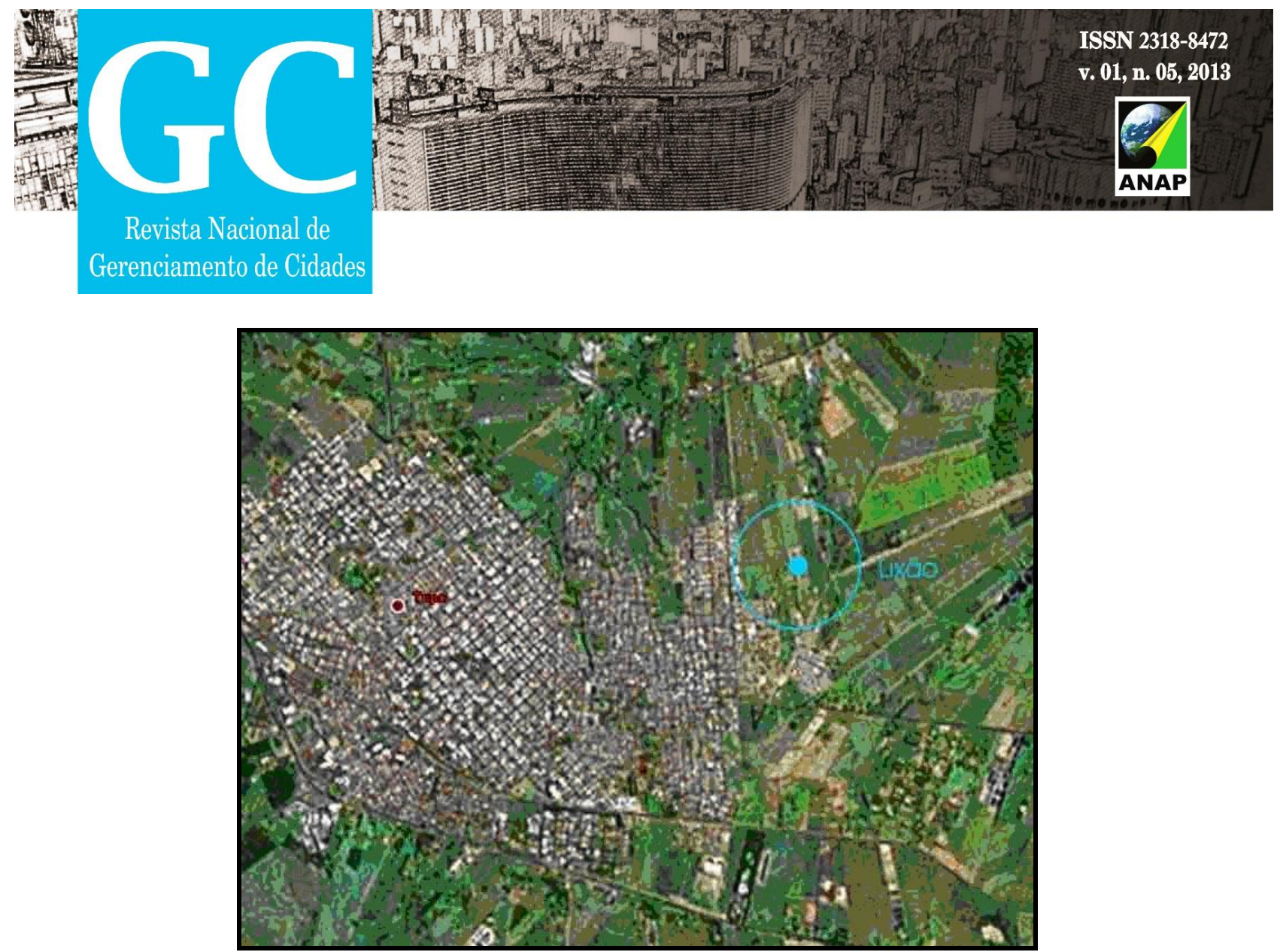

Figura 1. Localização do lixão urbano de Tupã (SP). Org. Hamada (2006).

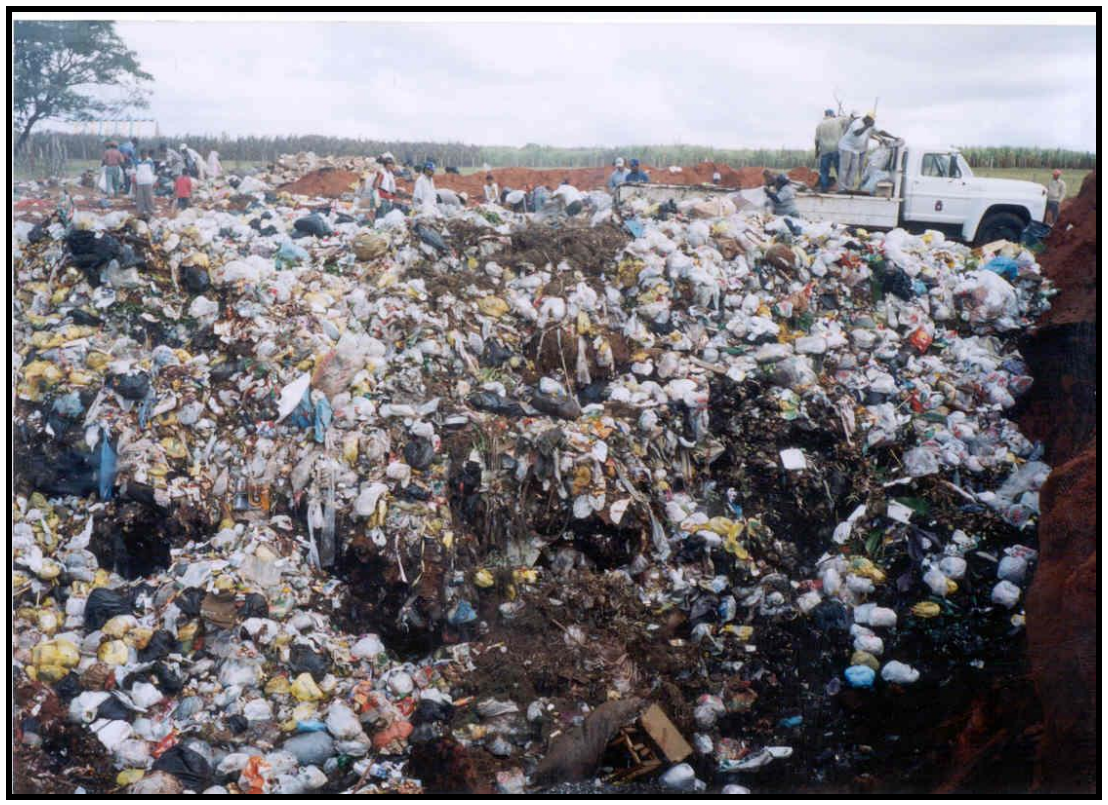

Figura 2. Vista parcial do lixão urbano de Tupã (SP). Fonte: Seolin Dias (mar. 2002). 


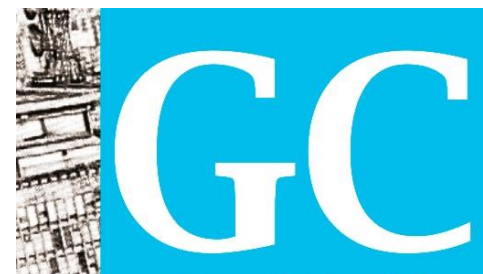

Revista Nacional de

Gerenciamento de Cidades

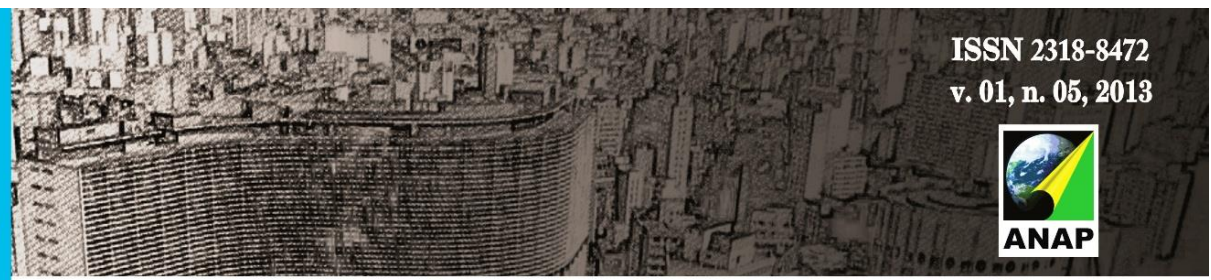

\section{Lixão urbano de Presidente Prudente:}

Já o lixão urbano de Presidente Prudente também se localiza a cerca de seis quilômetros do centro urbano, e de fácil acesso. Esse depósito com cerca de $90 \mathrm{~m}^{2}$. recebe aproximadamente 200 toneladas diárias de lixo (O ESTADÃO, 2008) (Figura 3). Apesar de ser denominado como "desativado" continua em plena atividade, com presença de trabalhadores diariamente (Figura 4).

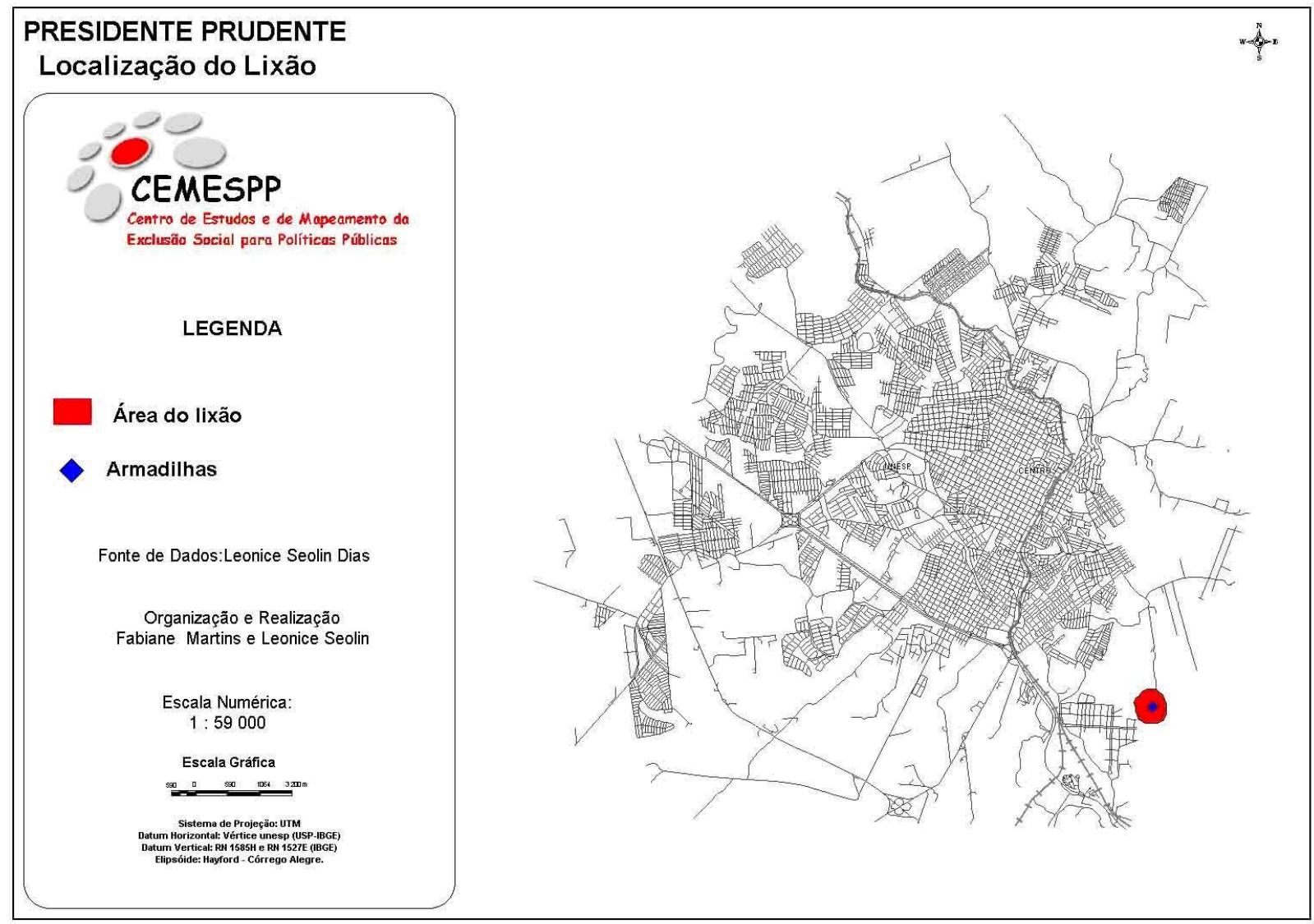

Figura 3. Localização do lixão de Presidente Prudente (SP). 

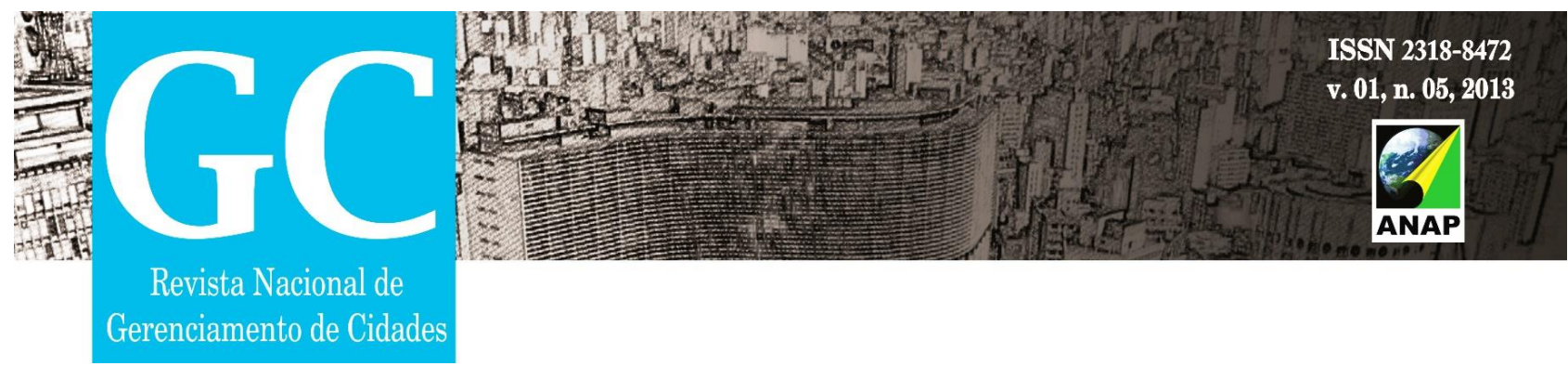

Gerenciamento de Cidades
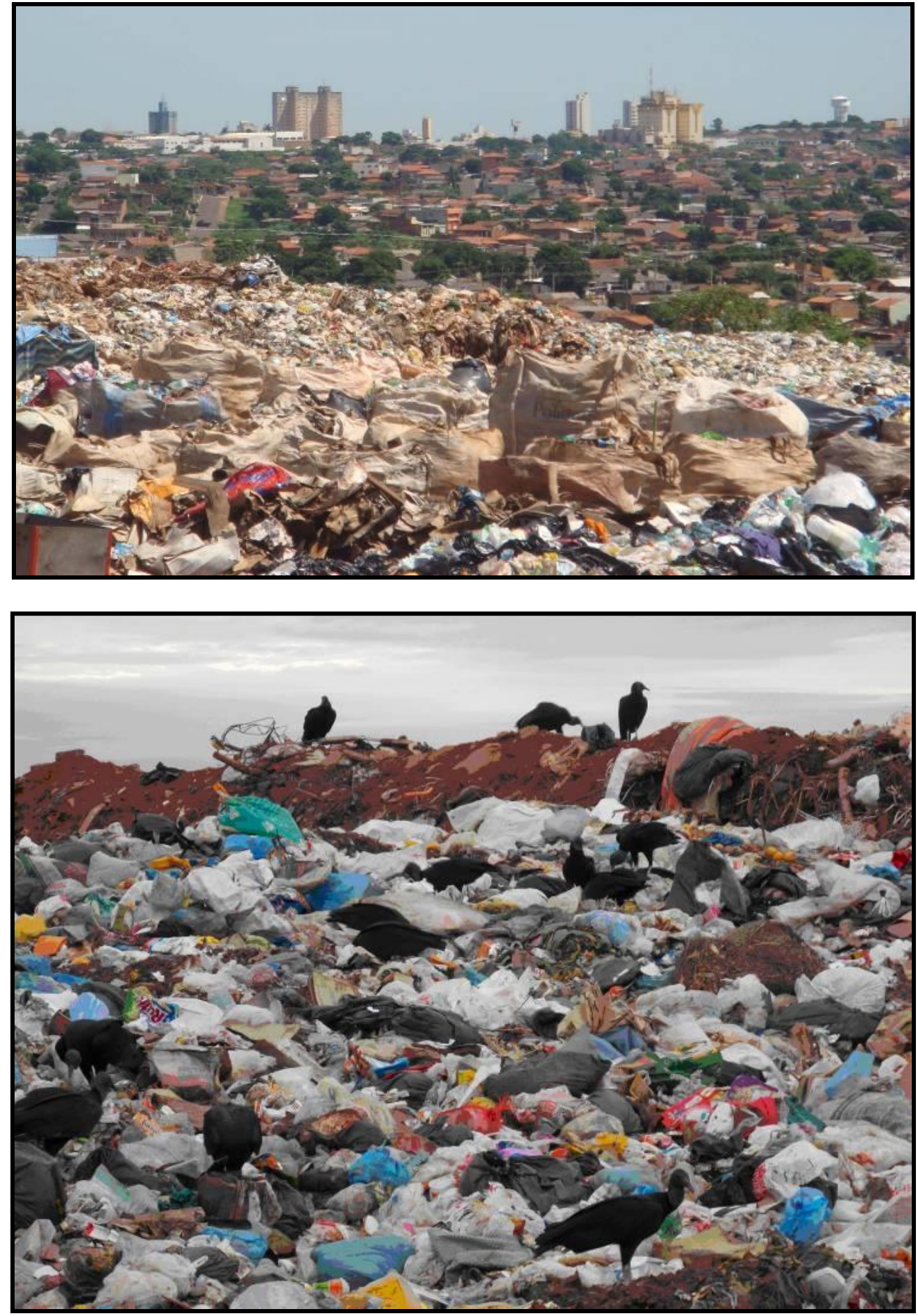

Figura 4. Vista parcial do lixão de Presidente Prudente (SP).

Fonte: Foto 1(out. 2006) e Foto 2 (set. 2013) Seolin Dias (2013). 


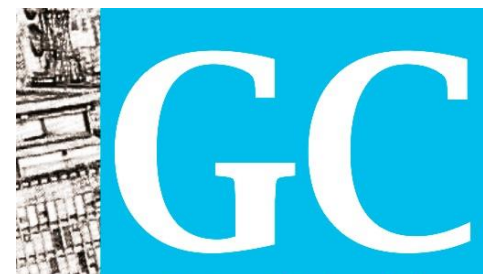

Revista Nacional de

Gerenciamento de Cidades

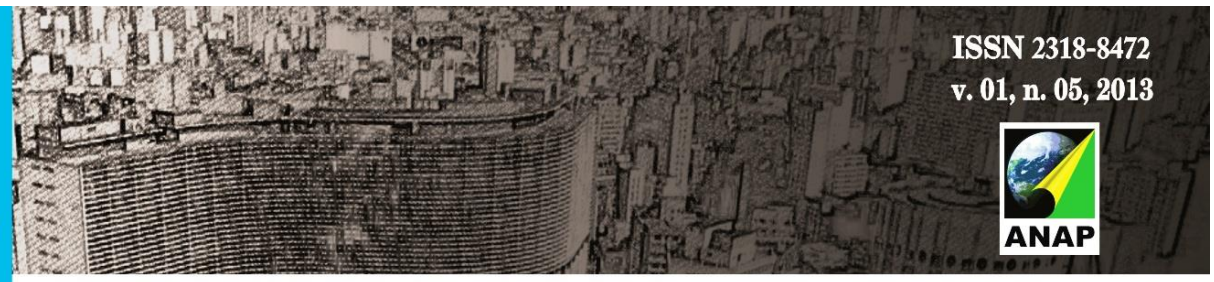

No lixão de Presidente Prudente, conforme figura 5, observa-se a presença de aves e animais domésticos circulando pelo depósito, como cachorros e gatos, que podem transmitir doenças. Mencionamos, ainda, a presença de dípteros, com ênfase às moscas, que possuem importância sanitária, devido a veiculação de patógenos causadores de doenças infecciosas e parasitárias aos homens e animais domésticos (GREENBERG, 1971).

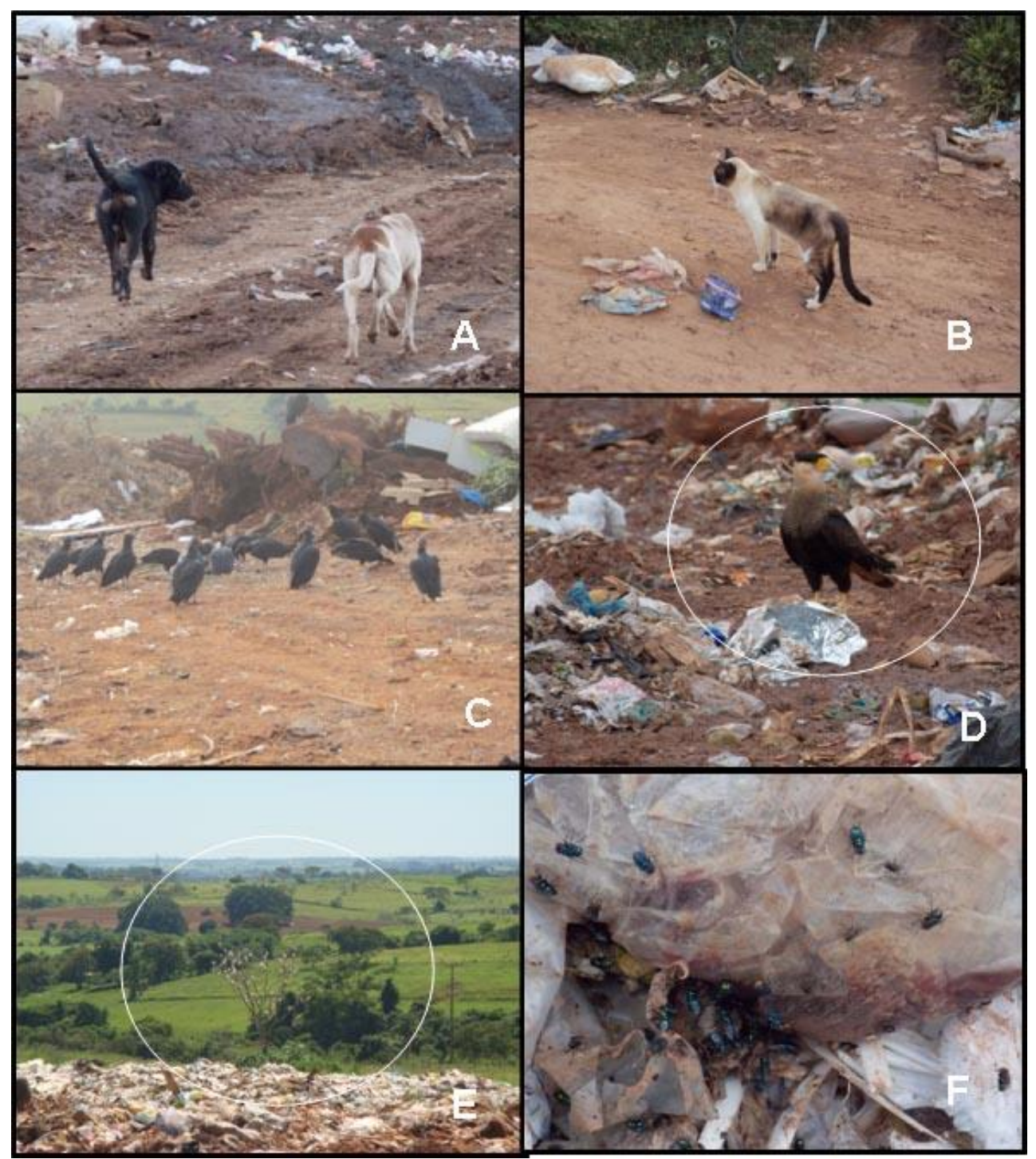

Figura 4: Lixão de Presidente Prudente: Animais domésticos, aves e insetos (moscas) que freqüentam o lixão de Presidente Prudente (SP).

Fonte: Seolin Dias (set. 2013). 
Revista Nacional de

Gerenciamento de Cidades

Acrescentam-se, ainda, na lista dos frequentadores desse lixão, à procura de alimentos, outros animais como: gado, cavalo e o homem (Figura 5).

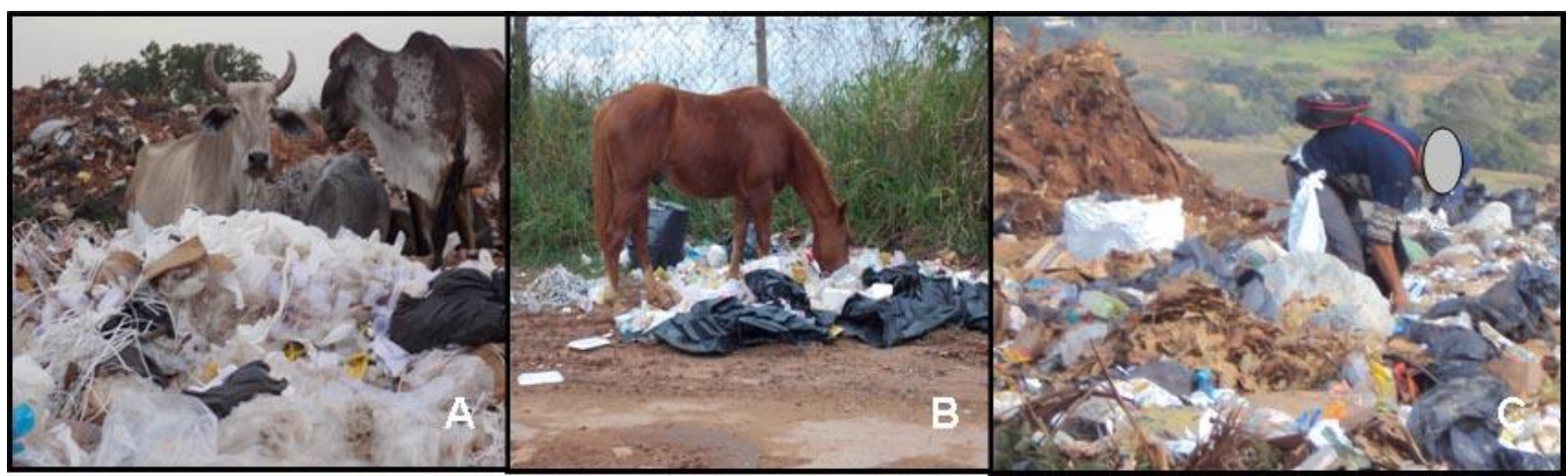

Figura 5: Lixão de Presidente Prudente: a) $O$ gado e cavalo se alimentando de lixo humano que está repleto de sacos plásticos; b) várias pessoas frequentam o local, diariamente, em busca do sustento diário (alguns catadores procuram materiais; e, outros, buscam encontrar sobras de alimentos aproveitáveis). Fonte: Seolin Dias (set. 2013).

\section{Aplicação dos formulários:}

O levantamento dos dados em Tupã deu-se no período de maio a junho de 2001 (30 meses), utilizando-se um questionário com 10 quesitos aplicados a 30 moradores (18 mulheres e 12 homens) circunvizinhos ao lixão, de várias idades e graus de escolarização. As principais questões foram respondidas com simples sim ou não para os quesitos considerados (SEOLIN DIAS, HAMADA, 2006). De igual modo ocorreu em Presidente Prudente (SP), questionário aplicado a 30 moradores (15 mulheres e 15 homens), diferindo o período, que foi de novembro a dezembro de 2010.

\section{RESULTADOS E DISCUSSÃO}

No levantamento efetuado no município de Tupã, observa-se um número significativo de moradores que identificaram a presença de fatores insalubres, 


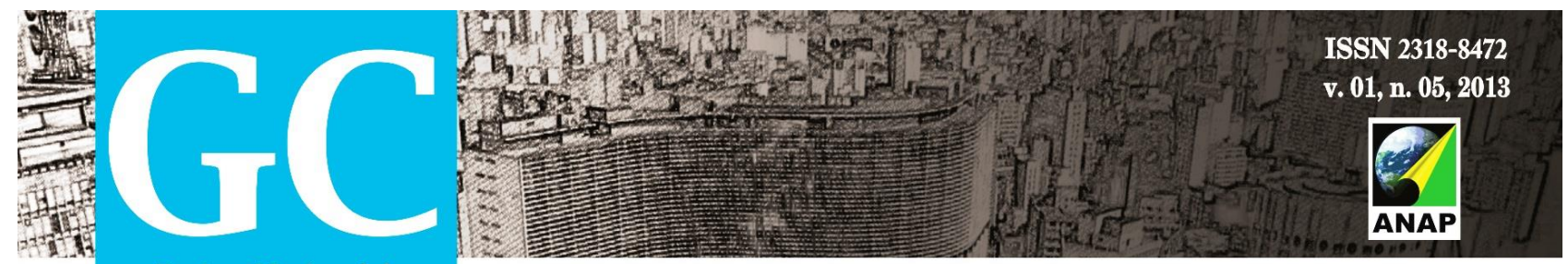

Revista Nacional de

Gerenciamento de Cidades

representando $33,3 \%$ para ratos, $76,7 \%$ para baratas, $86,7 \%$ para moscas, $90 \%$ para odores fétidos e $90 \%$ para a fumaça (Figura 6).

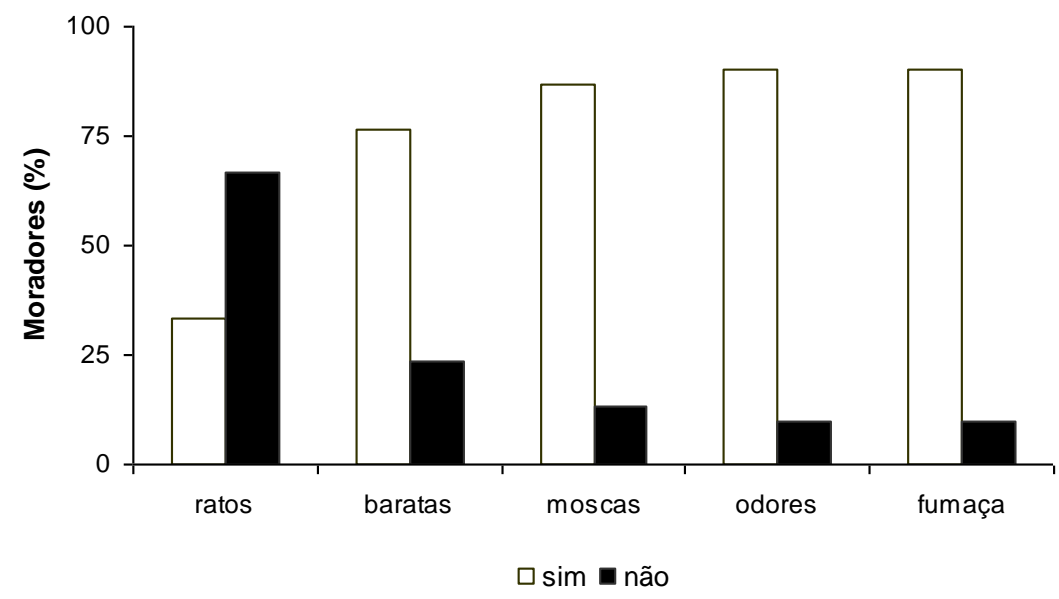

Figura 9: Opinião quanto a fatores bióticos e abióticos que incomodavam os moradores circunvizinhos ao lixão do município de Tupã (nov. 2001).

Já com relação aos dados do trabalho realizado em Presidente Prudente, os moradores que identificaram a presença de fatores insalubres discriminaram 16,6\%(05) para ratos, 30\% para baratas, 93,3\% para moscas, 93,3\% para odores fétidos e $100 \%$ para a fumaça (Figura 10).

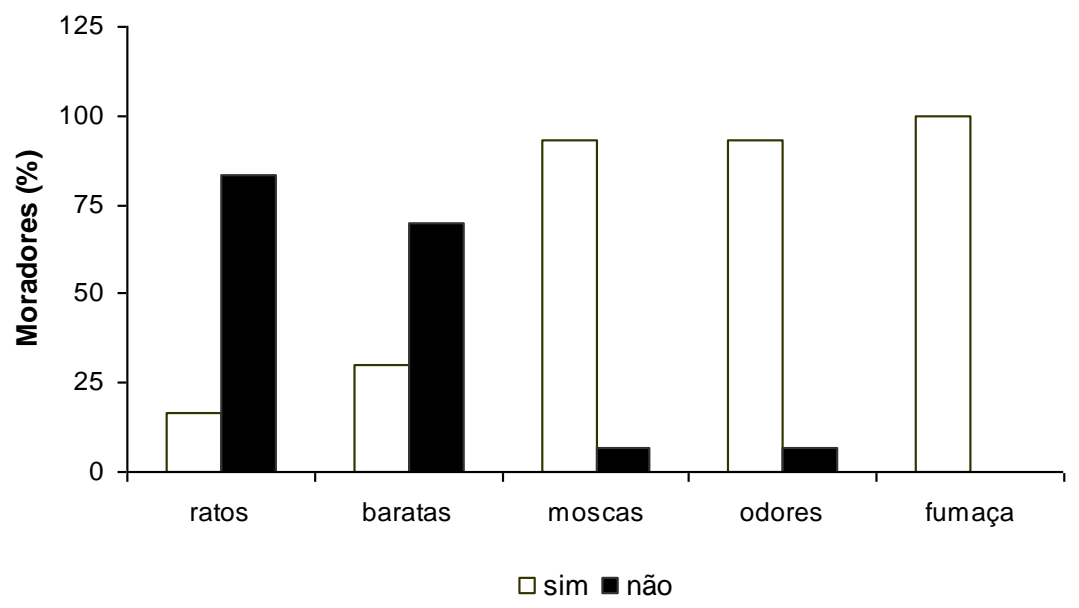

Figura 7: Opinião quanto a fatores bióticos e abióticos que incomodavam os moradores circunvizinhos ao lixão do município de Presidente Prudente (dez. 2010). 
Revista Nacional de

Gerenciamento de Cidades

Comparando os resultados dos dois locais, observa-se que diferem com relação a presença de ratos e baratas nas residências. Possivelmente, tal fato ocorreu porque os moradores de Tupã residiam mais próximo ao depósito de resíduos do que os de Presidente Prudente. Já as menções para as moscas e os fatores abióticos (odores e fumaça), praticamente foram iguais para os moradores dos dois municípios estudados.

\section{Formas usuais de disposição final dos resíduos}

Como é sabido, a disposição final dos resíduos sólidos urbanos é a última fase de um sistema de limpeza urbana, efetuada imediatamente após a coleta. Em alguns casos, entretanto, antes de ser disposto, o lixo é processado; isto é, sofre algum tipo de beneficiamento visando melhores resultados econômicos, sanitários e/ou ambientais.

Várias são as formas de tratamento e disposição final aplicáveis ao lixo, como:

- compactação: de acordo com Monteiro (2006), trata-se de um processamento que reduz o volume inicial de lixo de 1/3 a 1/5, favorecendo o seu posterior transporte e disposição final.

- trituração: Consiste na redução da granulometria dos resíduos através de emprego de moinhos trituradores, objetivando diminuir o seu volume e favorecer o seu tratamento e/ou disposição final.

- incineração: conforme Scalch et al. (2002), é um processo de decomposição térmica ocorrendo diminuição do peso, volume, eliminação da matéria orgânica e características de patogenicidade por meio da combustão controlada.

- compostagem: é um processo aeróbico de decomposição biológica e estabilização da matéria orgânica, para obtenção de um produto final estável, risco em composto húmicos e cuja utilização, no solo, não ofereça riscos ao meio ambiente (REIS et al., 2006).

- reciclagem: para Rodrigues e Cavinato (2003), significa "transformar os restos descartados por residências, fábricas, lojas e escritórios em matéria-prima para a fabricação de outros produtos". 

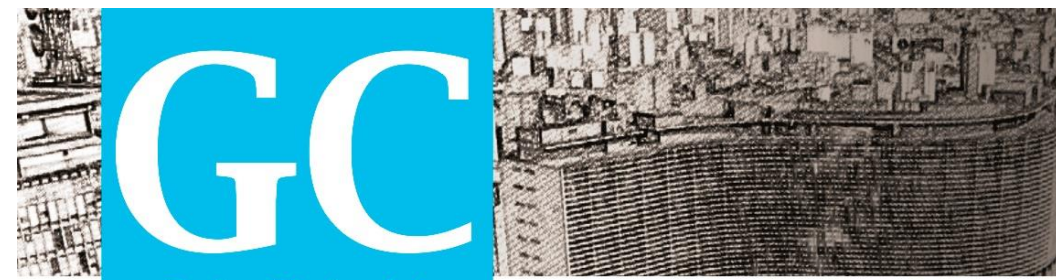

Revista Nacional de

Gerenciamento de Cidades

- aterro controlado: é uma técnica de dispor os resíduos sólidos no solo, cobrindo-os com uma camada de material inerte, e assim minimizar os danos ao meio ambiente, à saúde pública e à segurança (MONTEIRO, 2006).

- lixão: definido como o local no qual se deposita o lixo, sem projeto ou cuidado com a saúde pública e o meio ambiente, sem tratamento e sem qualquer critério de engenharia (BRAGA et al., 2002). É considerado, dentre as formas de tratamento e disposição final do lixo, o mais maléfico. Segundo Trípoli (2004), essa prática é a mais prejudicial ao homem e ao meio ambiente, sendo um dos principais problemas ambientais encontrados no Estado de São Paulo.

\section{Lixão: tem solução?}

Nos últimos anos, as discussões a respeito dos problemas ambientais ganharam destaque e a preocupação com o meio ambiente vem aumentando devido à degradação da natureza provocada pelo homem. O princípio ambiental da prevenção é principio fundamental que visa prevenir danos ao meio ambiente, já que o homem destrói com certa facilidade e para construir é bem mais difícil, mesmo para recuperar uma área degradada (DIAS; MARQUES, 2011). Tal princípio é implementado por meio de ações aplicadas pelo Estado em larga escala e também pela coletividade, conforme está disposto na nossa Constituição no seu artigo 225, caput " ...impondo-se ao Poder Público e à coletividade o dever de defendê-lo e preservá-lo para as presentes e futuras gerações“"

No Brasil, nos últimos anos, ocorreu uma diminuição da quantidade de lixões, mas ainda existem cerca de 2.900 em atividade e das 189 mil toneladas de resíduos sólidos produzidas por dia apenas $1,4 \%$ é reciclado. A Lei 12.305/2010, que institui a Política Nacional de Resíduos Sólidos, estabeleceu prazos ou limites temporais para algumas ações tais como a eliminação de lixões e a consequente disposição final ambientalmente adequada dos rejeitos até agosto de 2014. Segundo a lei, todos os lixões existentes no Brasil devem ser transformados em aterros sanitários (BRASIL, 2011). 
Revista Nacional de

Gerenciamento de Cidades

Segundo Brasil (2013), a meta é desafiadora, mas não impossível segundo avaliação dos especialistas que participaram da Conferência das Cidades em 2011. Hoje, 25\% dos municípios brasileiros dispõem de forma adequada os seus resíduos, o que equivale a aproximadamente $58 \%$ do total produzido no País.

Possivelmente, a diminuição dos lixões é problema solucionável desde que implantadas medidas corretas e eficazes, como a coleta seletiva em pareceria com a reciclagem e, semelhantemente, o uso dos resíduos orgânicos na produção de adubos ou na produção de energia, que auxiliariam na redução dos lixões e aterros sanitários.

Pode-se entender que o tratamento adequado dos resíduos urbanos e/ou industrial pode dar-se em três etapas: coleta seletiva (onde se encaminha os resíduos não orgânicos para reciclagem); o aterro sanitário (não deixando os resíduos orgânicos a céu aberto) e a compostagem (processo de transformação do líquido do lixo em produto aproveitável) (BRASIL, 2010; JACOBI; BESEN, 2011).

Apesar do programa de coleta seletiva do lixo ser uma prática que vem sendo cada vez mais difundida, não resolveria totalmente o problema dos resíduos sólidos inorgânicos, uma vez que "a coleta seletiva de lixo é um sistema de recolhimento de materiais recicláveis, tais como papéis, plásticos, vidros, metais e orgânicos, previamente separados na fonte geradora. Esses materiais são vendidos às indústrias recicladoras ou aos sucateiros" (CEMPRE, 1999). Dentre as formas de redução de resíduos, este programa aliado ao aterramento que reduz em até $50 \%$ o volume dos resíduos inorgânicos e 10\% dos resíduos orgânicos, proporcionaria maiores ganhos ambientais, pois facilita o aterramento do material exposto (IETEC, 1999).

Constata-se que um programa de reciclagem bem conduzido tende a desenvolver na população uma nova mentalidade sobre questões que envolvem a economia e a preservação do meio ambiente.

Como relação a pergunta a acima, possivelmente, existem soluções para o tratamento adequado do lixo nos grandes e pequenos centros urbanos brasileiros que já provaram ser eficientes, como é o caso do município de Tupã (SP) que eliminou o antigo lixão e garantiu maior controle sobre a destinação do lixo coletado na cidade. Esse 

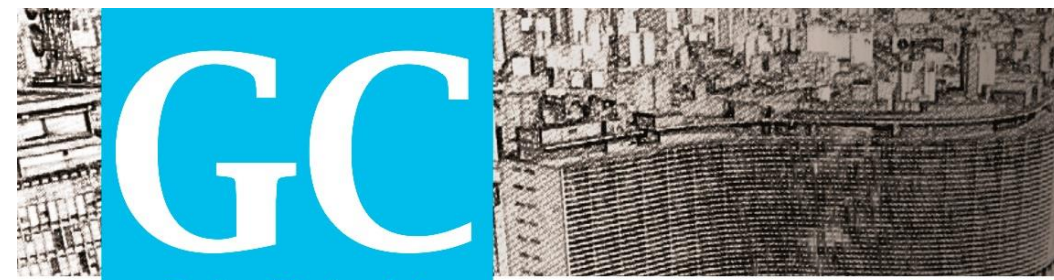

Revista Nacional de

Gerenciamento de Cidades

município conta hoje com locais adequados para o depósito de resíduos sólidos licenciados pela CETESB, e mantém o "Projeto Reciclar é Legal”, responsável pela coleta seletiva (SÃO PAULO, 2013).

Essa ação beneficia o meio ambiente e a população, uma vez que com a implantação da coleta seletiva, segundo Seolin Dias e Hamada (2006) observam-se aspectos positivos do programa, resultando na redução significativa da maioria dos fatores insalubres em seu entorno, sendo agora identificados 3,3\% de ratos, 33,3\% de baratas, 33,3\% de moscas, $13,3 \%$ de odores fétidos e $10 \%$ de fumaça. Após a desativação do lixão, ficou evidente a relação entre os fatores insalubres e presença do lixão, não sendo mais detectados problemas com odores e fumaça e a redução de baratas e moscas.

\section{Educação ambiental e resíduos sólidos}

A coleta seletiva, além da conscientização, é uma questão de educação ambiental. Uma das formas de levar a educação ambiental à comunidade é a ação direta do professor na sala de aula, e em atividades extracurriculares. Pode ela ser promovida também em outras atividades, como leituras, trabalhos escolares, palestras, debates e pesquisas.

Para Shitsuka et al (2009), a Educação Ambiental é importante na conscientização e formação de pessoas que pratiquem regularmente a reciclagem, o reuso de materiais e o tratamento correto de resíduos sólidos das diversas categorias. Dessa forma, diminuem-se os custos e o uso de materiais originais e diminui-se o impacto ambiental, para que as gerações futuras possam desfrutar de um mundo melhor.

Já para Dias (2000), cuidar do ambiente é tarefa diária de todos, ao final de cada dia devemos ter dado nossa contribuição, além de nos informarmos sobre as questões ambientais e isso também faz parte da cidadania.

Diante disso, acrescentamos ainda que:

[...] a Educação Ambiental desponta na perspectiva de gerar novos valores, visando a construção da racionalidade ambiental, objetiva ainda 
inserir nos processos educativos temas que discutam e promovam a melhoria do ambiente e da qualidade de vida... surge como instrumento capaz de provocar na sociedade as mudanças de comportamento requeridas pela realidade ambiental. A reciclagem do lixo, por exemplo, assume um papel fundamental na preservação do meio ambiente. Não obstante, é imprescindível que sejam revistos os padrões atuais de consumo, de modo que desperte nas pessoas uma preocupação em gerar quantidades cada vez menores de lixo,evitando desperdícios e reutilizando, ao máximo possível, embalagens que seriam descartadas. Tal mudança de atitude será fruto de uma Educação Ambiental permanente, com reflexos diretos na qualidade de vida da população (SHITSUKA, 2009; apud MARTINS, 2004):

\section{CONSIDERAÇÕES FINAIS}

Como se sabe, um lixão urbano pode causar sérios danos ao meio ambiente. Nos resultados do presente estudo observou-se que a presença desse depósito em determinado local causa transtornos não só ao local, como às comunidades vizinhas.

Cabe ao poder público, uma disposição final e adequada do lixo para prevenção e preservação da qualidade do meio ambiente e da saúde da população, principalmente aquela que seja circunvizinha a lixões urbanos.

Segundo Seolin Dias e Hamada (2006), programa de coleta seletiva deve ser concebido considerando-se todo o sistema de manejo de resíduos, inclusive o sistema de disposição final, o que pode representar para o poder público, custos globais compatíveis, principalmente quando se consideram os ganhos com saúde pública.

A solução para os lixões está efetivamente na vontade política e destinação de recursos para que se implantem sistemas tecnicamente adequados de disposição final do lixo, cumprindo-se as exigências das normas estabelecidas a partir da Constituição Federal e conscientizando a população por meio da educação ambiental. Essa atitude pode trazer enormes benefícios ao meio ambiente e à saúde da população.

\section{REFERÊNCIAS}



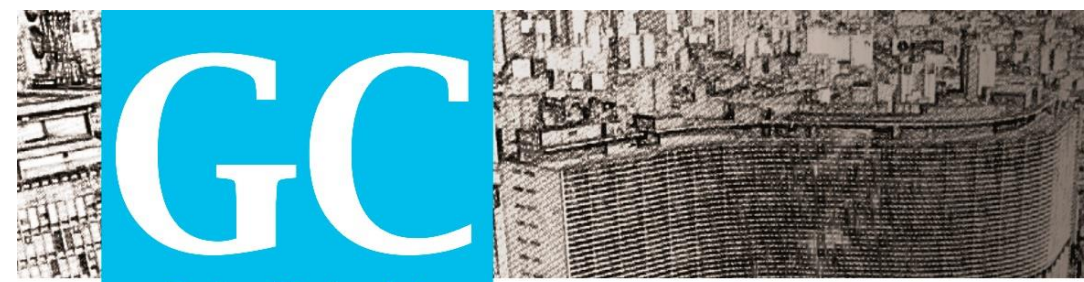

Revista Nacional de

Gerenciamento de Cidades

BRAGA et al. Introdução à Engenharia Ambiental. São Paulo: Prentice Hall, 2002. v. 1, $305 \mathrm{p}$.

BRASIL - MINISTÉRIO DO MEIO AMBIENTE: Plano nacional de resíduos sólidos.

Disponível

em:<http://www.mma.gov.br/estruturas/253/_publicacao/253_publicacao02022012041757.pdf>.

Acesso em out. 2013.

BRASIL - Jornal da Câmara. Política Nacional de resíduos sólidos. Disponível em: $<$ http://www.camara.gov.br/internet/agencia/pdf/especialconferencia.pdf>. Acesso em out. 2013).

BRASIL - MINISTÉRIO DO MEIO AMBIENTE. Manual para implantação de compostagem e de coleta seletiva no âmbito de consórcios públicos. Disponível em: <http://www.mma.gov.br/estruturas/srhu_urbano/_arquivos/3_manual_implantao_compostagem_c oleta_seletiva_cp_125.pdf>. Acesso em out. 2013.

DIAS, L. S; MARQUES, M. D. Meio ambiente e a importância dos principíos ambientais, Revista do Fórum Ambiental (Online), V. 07, N. 05, 2011.

DIAS, G. F. Educação ambiental. 6 ed. São Paulo: Gaya, 2000.

GREENBERG, B. Flies and diseases. Ecology, classification and biotic association. Princeton: Princeton University, 1971. 856 p.

IPT/CEMPRE. Lixo Municipal: manual de gerenciamento integrado São Paulo: Instituto de Pesquisas Tecnológicas (IPT), e Compromisso Empresarial para Reciclagem (CEMPRE), 1995. 278 p. 

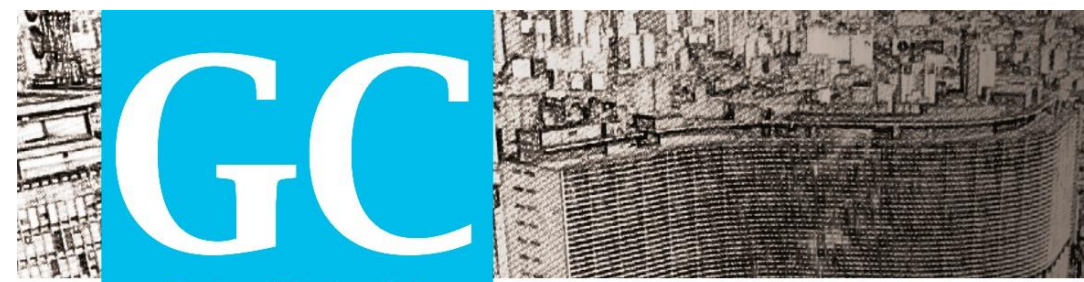

Revista Nacional de

Gerenciamento de Cidades

JACOBI, P. R.; BESEN, G. R. Gestão de resíduos sólidos em São Paulo: desafios da sustentabilidade. Estudos Avançados, v. 25, n. 71, 2011

MARTINS, J. C. V. A formação de atitudes e o comportamento público do brasileiro em relação ao lixo que produz. In: Revista Holos, 2004. Disponível em:

<http://www2.ifrn.edu.br/ojs/index.php/HOLOS/article/view/45 >. Acesso em out. 2013.

MONTEIRO, A. E. Índice de Qualidade de Aterros Industriais IQRI. 2006.

201f. Dissertação (Mestrado em Engenharia Civil) - Instituto Alberto Luiz Coimbra de Pós Graduação e Pesquisa em Engenharia, Rio de Janeiro

O ESTADÃO de São Paulo (Jornal On-line). Apesar de desativado, lixão recebe 200 t de dejetos por dia, em Prudente. Disponível em:

<http://www.estadao.com.br/noticias/impresso, apesar-de-desativado-lixao-recebe-200-t-dedejetos-por-dia-em-prudente,251894,0.htm>. Acesso em out. 2013.

REIS, M. F. P.; ELLWANGER, R. M.; HOFFMANN, M. S. A produção de composto orgânico com qualidade em uma unidade de triagem e compostagem. Open Journal Systems, v. 1, 2006.

RODRIGUES, F. L.; CAVINATO, V. M. Lixo: de onde vem?, para onde vai?. São Paulo: Moderna, 1997.

SÃO PAULO - GOVERNO DO ESTADO DE SÃO PAULO: Aterro sanitário de Tupã é modelo na região. Disponível em:

<http://www.saopaulo.sp.gov.br/spnoticias/lenaimprensa.php?id=200289\&q=Aterro+sanit\%E1 rio+d e+Tup\%E3+\%E9+modelo+na+regi\%E3o>. Acesso em out. 2013.

SCHALCH et al. Gerenciamento de resíduos de serviços de saúde, São Carlos, SP. p. 27-28, 2002. 

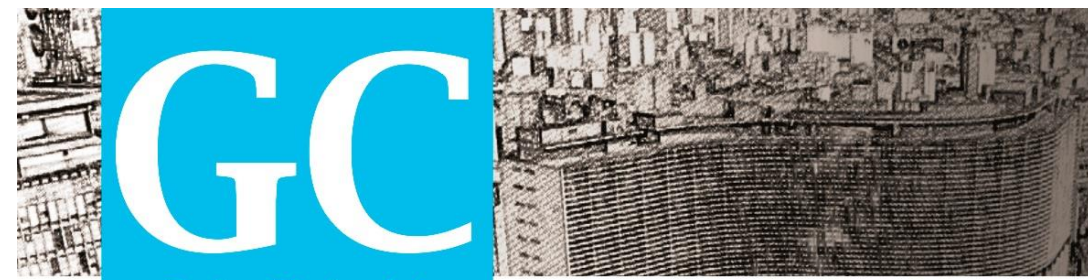

Revista Nacional de

Gerenciamento de Cidades

SEOLIN DIAS, L. ; MEDINA, A. O. ; ALMEIDA, M. S. R. ; SANTAREM, V. A. Dinâmica Populacional de Moscas Calliphoridae e Muscidae no Lixão de Presidente Prudente, São Paulo, Brasil. In: XII Encontro Anual de Pesquisa Institucional e Iniciação Científica da Unoeste, 2007,Presidente Prudente. CD-ROM: Anais... Encontro de Ensino, Pesquisa e Extensão da Unoeste. Presidente Prudente : Unoeste, 2007.

SEOLIN DIAS, L. AKASKI, K. T.; GIUFFRIDA, R.; GUIMARÃES, R. B.; SANTARÉM, V. A. Estruturas parasitárias veiculadas por moscas em quatro biótopos de Teodoro Sampaio, São Paulo, Brasil. XXIII Congresso Brasileiro de Parasitologia e III Encontro de Parasitologia do MERCOSUL. Anais... do evento (CD-ROM), 2013, Florianópolis (SC).

SEOLIN DIAS, L. ; HAMADA, J. . Benefícios do Programa de Coleta Seletiva na Salubridade da População no Entorno do Lixão de Tupã, São Paulo, Brasil. Fórum Ambiental da Alta Paulista, v. 2, p. 01-07, 2006.

SHITSUKA, R. et al. Educação ambiental e a conscientização da sociedade no tratamento do lixo. Centro Científico Conhecer - Enciclopédia Biosfera, Goiânia, v.5, n.8, 2009.

TAVARES, C. R. G.; BARROS JUNIOR, C. A situação do resíduo sólido urbano da cidade de Maringá. Anais... Seminário Nacional Sobre Resíduos Sólidos. Recife: ABES, 2000.

TRIPOLI, R. Aula magna do curso de Engenharia Ambiental. Engenharia Ambiental: pesquisa e tecnologia, Espírito Santo do Pinhal - SP, v. 1, n. 1, p. 1-8, 2004. 